\title{
Absence of Correlation between IL-28B Gene Polymorphisms and the Clinical Presentation of Chronic Hepatitis B in an Amazon Brazilian Population
}

\author{
Simone Regina Souza da Silva Conde, ${ }^{1,2}$ Luciana L. Rocha, ${ }^{1}$ Vanessa M. Ferreira, ${ }^{1}$ \\ Julius Caesar Mendes Soares Monteiro, ${ }^{1}$ Nathália Karla Fonseca Filgueiras, ${ }^{1}$ \\ Pedro Alves de Almeida Lins, ${ }^{1}$ Bruna Tereza Silva dos Santos, ${ }^{1}$ Felipe Bonfim Freitas, ${ }^{3}$ \\ Ednelza da Silva Graça, ${ }^{3}$ Sâmia Demachki, ${ }^{1}$ Marialva Tereza Ferreira de Araújo, ${ }^{1}$ \\ Ricardo Ishak, ${ }^{3}$ and Antonio C. R. Vallinoto ${ }^{3}$ \\ ${ }^{1}$ School of Medicine, Institute of Health Sciences, Federal University of Pará, Umarizal, 66050-380 Belém, PA, Brazil \\ ${ }^{2}$ Holy House of Mercy Foundation of Pará, Umarizal, 66050-380 Belém, PA, Brazil \\ ${ }^{3}$ Virology Laboratory, Institute of Biological Sciences, Federal University of Pará, Guamá, 66075-110 Belém, PA, Brazil
}

Correspondence should be addressed to Antonio C. R. Vallinoto; vallinoto@ufpa.br

Received 22 January 2014; Accepted 21 March 2014; Published 10 April 2014

Academic Editor: Giuseppe Murdaca

Copyright (C) 2014 Simone Regina Souza da Silva Conde et al. This is an open access article distributed under the Creative Commons Attribution License, which permits unrestricted use, distribution, and reproduction in any medium, provided the original work is properly cited.

Objective. The present study investigated the prevalence of the IL-28B polymorphisms rs 12979860 and rs 8099917 in chronic hepatitis B patients from a case study in Eastern Amazonia. Methods. In total, 65 chronically infected HBV patients and 97 healthy subjects who were anti-HBc and anti-HBs positive (control group) were evaluated between May 2011 and December 2012. The groups of patients were designated as inactive carriers, chronic hepatitis without cirrhosis, and chronic hepatitis with cirrhosis based on clinical, pathological, biochemical, hematological, and virological variables. The patients were genotyped using quantitative realtime PCR. Results. The frequencies of the rs12979860 polymorphism were similar between the infected group (32.3\% CC, $41.5 \%$ CT, and $26.2 \mathrm{TT}$ ) and the control population (35\% CC, 47.4\% CT, and 17.6\% TT), and the frequencies of the rs 8099917 polymorphism (7.7\% GG, 35.4\% GT, and 56.9\% TT versus 7.2\% GG, 35.1\% GT, and 57.7\% TT) were also similar in both groups. The associations between the rs12979860 and rs8099917 polymorphisms and the clinical manifestations were not statistically significant. Conclusion. In conclusion, these polymorphisms had a similar distribution between infected and control groups, indicating that they were not associated with susceptibility and the clinical evolution of hepatitis B in the examined population.

\section{Introduction}

Hepatitis B virus (HBV) infections are a serious global public health problem. An estimated two billion people have already come into contact with this virus, and approximately 350 million individuals are chronic carriers worldwide. Over one million deaths from this virus are reported annually [1-3].

The endemicity of HBV in Brazil is quite heterogeneous; the disease is the most prevalent in the north region of the country that encompasses Western Amazonia, especially in the zone that covers the states of Acre, Amazonas, Rondônia, and Roraima [4, 5]. In 2011, there were 172 confirmed cases of hepatitis B in the state of Pará, representing approximately $9 \%$ of the cases in the north region [6].

HBV infection results in a wide spectrum of clinical manifestations, ranging from an acute self-limiting disease to chronic disease. It is possible to detect inactive carriers and chronic hepatitis patients with or without cirrhosis, which are diseases that result in approximately 500,000 deaths annually worldwide due to liver failure and hepatocellular carcinoma [7-9].

One important factor related to the different clinical manifestations of the disease is interleukin-28B (IL-28B), 
a cytokine discovered in 2003 that is part of the $\gamma$ interferon family [10]. The gene for IL-28B is located on the long arm of chromosome 19 at position 19q13.13 [11, 12]. All the subtypes of interferon- $\gamma$ play an important role in antiviral immunity, especially in the IL-28B-mediated antiviral defense against hepatotropic viruses, such as $\mathrm{HBV}$ and hepatitis $\mathrm{C}$ virus (HCV) $[13,14]$.

Single nucleotide polymorphisms (SNPs) have been found in the IL-28B gene at positions rs12979860 and rs8099917, which are located 3 kilobases upstream of the gene and have recently been associated with the response of certain individuals to viral infections $[15,16]$.

The IL-28B polymorphisms have been associated with both the spontaneous clearance of $\mathrm{HCV}$ and the response to antiviral treatment, which play a key role in the resolution of the infection. Considering that $\mathrm{HBV}$ and $\mathrm{HCV}$ have similar natural histories, levels of pathogenesis, and modes of transmission, genetic variants of IL-28B may also have a functional role during chronic HBV infection [12].

This study was prompted by the lack of information on the relationship between the genetic profile of IL-28B and $\mathrm{HBV}$ infections in Eastern Amazonia, an endemic area for this virus. Therefore, the primary aim of this study was to examine a possible association between the polymorphisms rs12979860 and rs8099917, HBV, and the clinical manifestations of this infection.

\section{Materials and Methods}

2.1. Study Population. This cross-sectional, observational, analytical, and descriptive study was performed in an outpatient clinic for liver diseases at the Holy House of Mercy Foundation of Pará and the Virology Laboratory at the Institute of Biological Sciences, Federal University of Pará in the city of Belém, PA, Brazil.

The study population included 65 patients with chronic HBV whose samples were collected from October 2011 to June 2012. The study included patients who were HBsAg positive for more than six months, with or without a positive HBeAg test, older than 18 years of age, and either male or female. Patients were excluded who had coinfections (human immunodeficiency virus (HIV) or HCV), had previously received treatment, and did not agree to participate.

The control population included 97 healthy subjects of both sexes, older than 18 years of age, who had previously exhibited spontaneous HBV seroconversion (anti-HBc and anti-HBs positive) but were negative for $\mathrm{HCV}$ and HIV infections.

2.2. Data Collection. Demographic variables including gender, age, birthplace, occupation, educational level, and marital status were examined. The patients were clinically classified into two groups according to clinical, sonographic, endoscopic, and histopathological criteria when possible as follows:

(i) inactive carriers of $\mathrm{HBV}(n=26)$ : characterized by consistently normal alanine aminotransferase (ALT) and aspartate aminotransferase (AST) levels over a minimum period of one year, $\mathrm{HBeAg}$ negative, antiHBeAg positive, HBV-DNA < $2000 \mathrm{IU} / \mathrm{mL}$, or/and significant histopathological lesions $(A \leq 1$ and $F \leq$ 1, METAVIR classification);

(ii) chronic hepatitis B carriers with $(n=12)$ or without cirrhosis $(n=27)$ : characterized by clinical changes, liver tests, HBeAg positive or negative, HBV-DNA > $2000 \mathrm{IU} / \mathrm{mL}$, and significant histopathological lesions ( $F \geq 2$ and $<4$, METAVIR classification); the diagnosis of cirrhosis included signs of hepatocellular failure, portal hypertension, or liver histopathology with a fibrosis score of 4 based on the METAVIR classification.

2.3. Laboratory Variables. Routine laboratory tests (blood count, AST, ALT, and gamma-glutamyl transpeptidase) and enzyme immunoassays to test for markers of infection (HBsAg, $\mathrm{HBeAg}$, anti-HBc, anti-HBs, and anti-HCV) were performed at the Laboratory of Clinical Analysis at the Holy House of Mercy Foundation of Pará. Anti-HIV tests and the quantification of the HBV viral load (HBV-PCR DNA quantification, Amplicor, ROCHE) were performed at the Central Laboratory of the Health Department of the State of Pará.

The data considered for this study included the tests performed closest to the collection period for the untreated patients and the tests performed just prior to antiviral therapy for the patients.

2.4. Collection and Sample Processing. Blood samples were taken for plasma and cell collection using vacuum collection tubes containing $5 \mathrm{~mL}$ of EDTA as an anticoagulant. The samples were subsequently sent to the Virology Laboratory at the Institute of Biological Sciences/Federal University of Pará, where aliquots of plasma and leukocytes were stored at $-70^{\circ} \mathrm{C}$ until use.

2.5. DNA Extraction. Total DNA was extracted from peripheral blood leukocytes at the Virology Laboratory at the Institute of Biological Sciences, Federal University of Pará, using a Puregene kit (Gentra Systems, Inc., USA) following the protocol for cell lysis, protein precipitation, DNA precipitation, and rehydration. The DNA samples were stored at $-20^{\circ} \mathrm{C}$ until use.

2.6. Genotyping the IL-28B Polymorphisms. Real-time PCR (qPCR) was used to genotype the rs12979860 and rs8099917 SNPs using TaqMan Gene Expression Assay AHCS19G and TaqMan Gene Expression Assay C__11710096_10 kits (Applied Biosystems, Foster City, CA, USA), respectively, following the technical procedures recommended by the manufacturer.

For the rs12979860 polymorphism, a custom-designed assay provided by Applied Biosystems was used. The following primer sequences were used in these assays: forward primer, $5^{\prime}$-GCCTGTCGTGTACTGAACCA-3'; reverse primer, $5^{\prime}$-GCGCGGAGTGCAATTCAAC-3'; allele C (VIC), $5^{\prime}$-TGGTTCGCGCCTTC-3'; allele T (FAM), 5'-CTGGTTCACGCCTTC-3'. For the rs8099917 
polymorphism, an assay predesigned by Applied Biosystems was used. The sequence context was $5^{\prime}$-TTTTGTTTTCCTTTCTGTGAGCAAT[G/T]TCACCCAAATTGGAACCATGCTGTA-3' ${ }^{\prime}$, in which allele $\mathrm{G}=\mathrm{VIC}$ and allele $\mathrm{T}=\mathrm{FAM}$.

The PCR reactions were prepared using TaqMan Universal PCR Master Mix components (Applied Biosystems), which contained nucleotides, buffer, UNG, AmpliTaq, and a passive reference dye (ROX). The reaction mixture contained $5.0 \mu \mathrm{L}$ of Master Mix, $3.5 \mu \mathrm{L}$ of $\mathrm{H}_{2} \mathrm{O}, 0.5 \mu \mathrm{L}$ of IL-28B assay components (primer set and probe), and $1.0 \mu \mathrm{L}$ of DNA from each sample. The final volume for each reaction was $10 \mu \mathrm{L}$.

A Step One Plus Real-Time PCR System (Applied Biosystems) was used to perform the qPCR experiments using the following cycling protocol: one cycle of $60^{\circ} \mathrm{C}$ for 2 minutes, one cycle of $95^{\circ} \mathrm{C}$ for 10 minutes, and 50 cycles of $95^{\circ} \mathrm{C}$ for 15 seconds and $60^{\circ} \mathrm{C}$ for 20 seconds.

The program StepOne v2.2 (Applied Biosystems) was used to interpret the reaction results, using the graphical representation of the VIC and FAM fluorophore emissions with respect to constitutive ROX emissions.

2.7. Histopathological Variables. Upon providing informed consent, the patients who had prothrombin activity less than or equal to $70 \%$ and platelets counts above 100,000 cells $/ \mathrm{mm}^{3}$ underwent a liver biopsy.

The liver biopsies were performed using a Trucut needle and were guided by ultrasound. Each biopsy was examined by the Pathological Anatomy Service at the Federal University of Pará following routine service. The samples were stained with hematoxylin-eosin, chromotrope aniline blue, Gomori reticulin, and Shikata's orcein.

The histopathological diagnoses followed the French METAVIR classification [17].

The assessment of the necroinflammatory histological activity index was performed by grouping the $A_{0}$ and $A_{1}$ patients into mild to moderate activity and the $A_{2}$ and $A_{3}$ patients into severe activity. The degree of fibrosis was grouped as mild to moderate $\left(F_{0}\right.$ to $\left.F_{2}\right)$ and advanced $\left(F_{3}\right.$ and $\left.F_{4}\right)$.

2.8. Data Analysis. Descriptive data analysis was performed to calculate the absolute and relative frequencies, measures of central tendency (mean, median, minimum, and maximum), and dispersion values (standard deviation).

Inferential analyses were also performed based on the characteristics of the data normality. A nonparametric ANOVA test was used for quantitative data, and Chi-square tests with or without a Yates correction, Mann-Whitney tests, Kruskal Wallis tests, and $G$ tests with Williams' correction for nominal or ordinal qualitative data were used for nonparametric data. The Hardy-Weinberg equilibrium was calculated to assess the frequency of genotypes.

The odds ratio (OR) and its respective 95\% confidence interval $(95 \% \mathrm{CI})$ were calculated to measure the degree of association between the genotypes and virus infections. The programs Epi Info 3.5.3 [18] and BioEstat 5.3 [19] were used to
TABLE 1: Genotypic and allelic frequencies of the polymorphisms rs12979860 and rs8099917 in the IL-28B gene in HBV patients and controls.

\begin{tabular}{|c|c|c|c|}
\hline Polymorphism & $\begin{array}{c}\text { HBV group } \\
n(\%)\end{array}$ & $\begin{array}{c}\text { Control group } \\
n(\%)\end{array}$ & $P^{\mathrm{a}}$ \\
\hline \multicolumn{4}{|l|}{ rs12979860 } \\
\hline \multicolumn{4}{|l|}{ Genotypes } \\
\hline CC & $21(32.3)$ & $34(35.0)$ & \multirow{3}{*}{0.5490} \\
\hline $\mathrm{CT}$ & 27 (41.5) & $46(47.4)$ & \\
\hline $\mathrm{TT}$ & $17(26.2)$ & 17 (17.6) & \\
\hline Total & $65(100.0)$ & $97(100.0)$ & \\
\hline \multicolumn{4}{|l|}{ Alleles } \\
\hline C & $69(53.1)$ & $114(58.8)$ & \multirow{2}{*}{0.3694} \\
\hline $\mathrm{T}$ & $61(46.9)$ & $80(41.2)$ & \\
\hline \multirow[t]{2}{*}{ Total } & $130(100.0)$ & $194(100.0)$ & \\
\hline & $P=0.1806^{\mathrm{b}}$ & $P=0.8324^{\mathrm{b}}$ & \\
\hline \multicolumn{4}{|l|}{ rs8099917 } \\
\hline \multicolumn{4}{|l|}{ Genotypes } \\
\hline GG & $05(7.7)$ & $07(7.2)$ & \multirow{3}{*}{0.9915} \\
\hline GT & $23(35.4)$ & $34(35.1)$ & \\
\hline $\mathrm{TT}$ & $37(56.9)$ & $56(57.7)$ & \\
\hline Total & $65(100.0)$ & $97(100.0)$ & \\
\hline \multicolumn{4}{|l|}{ Alleles } \\
\hline G & $33(25.4)$ & $48(24.7)$ & \multirow{2}{*}{1.00} \\
\hline $\mathrm{T}$ & 97 (74.6) & $146(75.3)$ & \\
\hline \multirow[t]{2}{*}{ Total } & $130(100.00)$ & $194(100.0)$ & \\
\hline & $P=0.5951^{\mathrm{b}}$ & $P=0.5626^{\mathrm{b}}$ & \\
\hline
\end{tabular}

${ }^{\mathrm{a} C h i-s q u a r e ~ t e s t . ~}$

${ }^{\mathrm{b}}$ Hardy-Weinberg law.

perform the analyses, and a level of $P \leq 0.05$ was established to reject the null hypothesis.

2.9. Ethical Considerations. All the patients in the study were analyzed according to the precepts of the Declaration of Helsinki and the Nuremberg Code, respecting the regulatory guidelines and rules for Research Involving Humans, according to Resolution 196/96 of the National Health Council. This project was approved by the Committee for Ethics in Research at the Holy House of Mercy Foundation of Pará.

\section{Results}

Of the 65 individuals chronically infected with HBV, $67.7 \%$ were male and had a median age of 48 years. In total, $63.1 \%$ of these patients were from the metropolitan area, and $36.9 \%$ were from rural areas. In addition, $78.5 \%$ of the patients were HBeAg negative.

In total, $40 \%$ of the patients were clinically diagnosed as inactive carriers, $41.5 \%$ as chronic hepatitis without cirrhosis, and $18.5 \%$ as chronic hepatitis with cirrhosis.

In analyzing the allelic frequency of the polymorphisms rs12979860 and rs8099917 within the IL-28B gene, both 


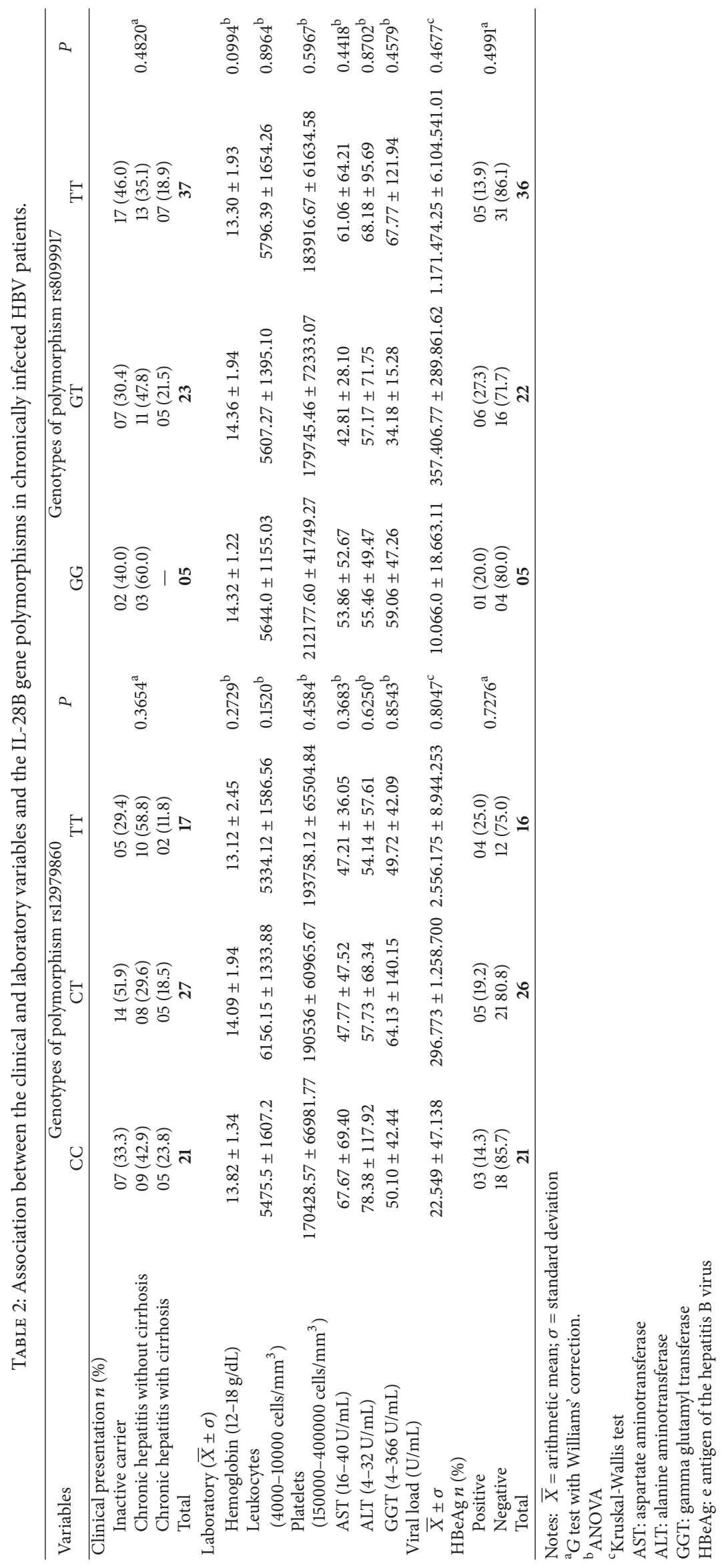


TABLE 3: Correlation between liver histopathology and the IL-28B gene genotype in chronically infected HBV patients.

\begin{tabular}{|c|c|c|c|c|c|c|c|c|}
\hline \multirow{2}{*}{$\begin{array}{l}\text { Liver histopathology } \\
\text { METAVIR }(n=32)\end{array}$} & \multicolumn{3}{|c|}{ Genotypes of the polymorphism rs12979860 } & \multirow{2}{*}{$P^{\mathrm{a}}$} & \multicolumn{3}{|c|}{ Genotypes of the polymorphism rs8099917 } & \multirow{2}{*}{$P^{\mathrm{a}}$} \\
\hline & $\mathrm{CC} n(\%)$ & $\mathrm{CT} n(\%)$ & $\mathrm{TT} n(\%)$ & & GG $n(\%)$ & GT $n(\%)$ & $\operatorname{TT} n(\%)$ & \\
\hline \multicolumn{9}{|l|}{$\begin{array}{l}\text { Inflammatory activity } \\
\text { periportal/periseptal }\end{array}$} \\
\hline 0 to 1 & $07(77.8)$ & $12(92.3)$ & $08(80.0)$ & \multirow{2}{*}{0.6058} & $04(100.0)$ & $10(83.3)$ & $13(81.3)$ & \multirow{2}{*}{0.5394} \\
\hline 2 to 3 & $02(22.2)$ & $01(7.7)$ & $02(20.0)$ & & - & $02(16.7)$ & $03(18.7)$ & \\
\hline \multicolumn{9}{|l|}{ Degree of fibrosis } \\
\hline 0 to 2 & $09(100.0)$ & $12(92.3)$ & $08(80.0)$ & \multirow{2}{*}{0.3137} & $03(75)$ & $11(91.7)$ & $15(93.7)$ & \multirow{2}{*}{0.6738} \\
\hline 3 to 4 & - & $01(7.7)$ & $02(20.0)$ & & $01(25)$ & $01(8.3)$ & $01(6.3)$ & \\
\hline
\end{tabular}

Notes: conventional signal used: ( - ) numerical data equal to zero but not as a result of rounding.

${ }^{\mathrm{a}} G$ test with Williams' correction.

TABLE 4: Haplotypes of the rs12979860 and rs8099917 polymorphisms in the IL-28B gene in chronically infected HBV patients and controls.

\begin{tabular}{lccc}
\hline Haplotypes & $\begin{array}{c}\text { HBV group } \\
n(\%)\end{array}$ & $\begin{array}{c}\text { Control group } \\
n(\%)\end{array}$ & $P^{\mathrm{a}}$ \\
\hline CCGT & $02(3.0)$ & $03(3.1)$ & \\
CCTT & $18(27.7)$ & $31(31.6)$ & \\
CTGT & $12(18.5)$ & $26(26.5)$ & \\
CTTT & $16(24.6)$ & $20(21.4)$ & 0.5667 \\
TTGG & $05(7.7)$ & $07(7.2)$ & \\
TTGT & $09(13.9)$ & $05(5.1)$ & \\
TTTT & $03(4.6)$ & $05(5.1)$ & \\
\hline Total & $65(100.0)$ & $97(100.0)$ & \\
\hline
\end{tabular}

Notes: conventional signal used: (-) numerical data equal to zero but not as a result of rounding.

${ }^{a} G$ test with Williams' correction.

HBV cases and controls were within the Hardy-Weinberg equilibrium $(P>0.05)$. The frequencies of the rs12979860 polymorphism were similar between the infected group (32.3\% CC, $41.5 \% \mathrm{CT}$, and $26.2 \mathrm{TT}$ ) and the control population (35\% CC, $47.4 \%$ CT, and $17.6 \%$ TT), and the frequencies of the rs8099917 polymorphism (7.7\% GG, 35.4\% GT, and 56.9\% TT versus $7.2 \% \mathrm{GG}, 35.1 \% \mathrm{GT}$, and $57.7 \% \mathrm{TT}$ ) were also similar in both groups (Table 1). Therefore, there was not any significant difference between the genotype frequencies in each group.

The association analysis between the clinical picture and the presence of polymorphisms as well as the laboratory characteristics, viral load, and serological status (Table 2) of the patients indicated that none of the associations between these variables were statistically significant. The allele and genotype frequencies of the rs 12979860 and rs8099917 polymorphisms were similar when compared to the clinical presentation, except to the absence of the genotype GG (rs8099917) among patients with chronic hepatitis with cirrhosis.

The associations between the polymorphisms and liver histopathology were also not significant (Table 3). Regarding the rs12979860 polymorphism, the genotype CC was absent and TT present with frequency of $20 \%$ among patients with degree of fibrosis 3 to 4 . Similarly, the data to rs8099917 polymorphism showed frequency of $18.7 \%$ to genotype TT among patients with inflammatory activity from 2 to 3 . On the other hand, the genotype GG was present only in patients with inflammatory activity from 0 to 1 .

A total of seven haplotypes were observed to patients and control groups (Table 4). The haplotype CCTT was the most frequent in both groups. But the haplotype association analysis of the polymorphisms between infected patients and the control group showed absence of association (Table 4).

\section{Discussion}

The infected study population in this study was predominately male $(67.69 \%)$ and averaged above 40 years of age, which is similar to recent studies $[3,20]$.

The genotypic and allelic proportions of the rs12979860 polymorphism were not significantly different, possibly due to the sample size of the infected group and the racial composition of the population. The CT genotype $(41.54 \%)$ was predominant in this group. Conversely, the predominant genotype in the literature is CC, especially in study populations with relatively little ethnic mixing [3, 21, 22].

Consistent with this study, several studies have reported no differences between the genotypic and allelic frequencies of the rs12979860 polymorphism of infected and control groups $[20,22]$. However, the slight predominance of the $\mathrm{C}$ allele (53.1\% for HBV and $58.8 \%$ in controls) found in this study was also seen in another study comparing chronically infected patients and patients with self-limiting infections in the USA [22].

Recent studies examining the rs8099917 polymorphism have not shown any significant data for genotypic and allelic frequencies. However, there was a predominance of the TT genotype upon comparing groups of chronically infected and cured patients [16], including larger groups, such as those with chronic HBV, hepatocellular carcinoma, self-limiting infections, and healthy control populations [23]. Consistent with the current literature, this study showed that there were no significant differences between frequencies $(P=0.9915$ for the genotypes and $P=1.00$ for the alleles) and that the TT genotype was prevalent in the population.

There were no significant associations between the polymorphisms rs12979860 and rs8099917 and the clinical 
presentations of the examined patients $(P=0.3654)$. The associations between clinical manifestations and these polymorphisms have been the subject of several studies, including associations with cirrhosis. However, the majority of these studies have been unable to identify any relationships [21]. Occasionally, the polymorphisms are not even addressed, especially in the case of the latter polymorphism.

Although this study did not find any significant associations, it offers important and valuable information on the associations between the liver histopathology of infected patients using the METAVIR score of inflammatory activity, the degree of hepatic fibrosis, and these polymorphisms (rs12979860 and rs8099917). There are no studies in the literature that have addressed this specific aspect when comparing the data for these different populations.

There were also no associations between any of the laboratory data and the genotypes of the two polymorphisms. Few studies have shown an association between chronic HBV patients and ALT levels. In this study, there was a higher prevalence of the CC and TT genotypes in the group with lower ALT levels for both polymorphisms [16]. However, for both the previous studies and the present study, there were no detectable differences between these genotypes and AST levels.

In this study, the viral load was also not associated with the polymorphisms rs12979860 and rs8099917 $(P=$ 0.8047 and $P=0.4677$ ). However, differences have been found in other studies, which showed a lower viral load in the CC genotype compared to patients with a CT + TT genotype for the first polymorphism [16] but not the second polymorphism.

Conversely, the lack of a relationship between the polymorphism haplotypes for the HBV infected cases and the cured controls was not observed for Asian populations [23]. Comparisons between the present studies and the Asian studies are difficult because the latter studies examined three polymorphisms (rs12979860 C/T, rs8099917 G/T, and rs12980275 G/A). These studies found a significant relationship between the C-T-A haplotype in patients who did not develop HCC $(P=0.01)$, but there were no significant associations between the T-G-G haplotype and progression to HCC $(P=0.11)$. Studies involving only the two polymorphisms are absent in the literature.

Studies examining the relationship between the IL-28B polymorphisms rs12679860 and rs8099917 and chronic hepatitis $B$ remain scarce in the current literature, and research related to this subject has only been published recently. This study is a pioneer in the field by analyzing a regional sample. Therefore, it is important to determine the implications of these new findings in terms of HBV infection.

\section{Conflict of Interests}

The authors declare that there is no conflict of interests regarding the publication of this paper.

\section{Acknowledgments}

The authors thank the patients and send them the best wishes. The present study was partially supported by a grant from the Brazilian National Council for Scientific and Technological Development $(\mathrm{CNPq})$ and Pró-Reitoria de Pesquisa e PósGraduação (PROPESP/UFPA)/Fundação de Apoio e Desenvolvimento da Pesquisa (FADESP).

\section{References}

[1] A. M. Almeida, D. I. da Silva, A. A. Guerra Jr., G. D. Silva, and F. D. A. Acurcio, "Efficacy of interferon (conventional, pegylated) and lamivudine for treatment of chronic hepatitis B: a systematic review," Cadernos de Saude Publica, vol. 25, no. 8, pp. 1667-1677, 2009.

[2] M. N. Silva, P. Bacellar, H. Martins, and M. M. Aguiar, "Hepatitis B-casuistic review of internal medicine outpatient consultations," Revista da Sociedade Portuguesa de Medicina Interna, vol. 14, pp. 140-145, 2007.

[3] M. J. Sonneveld, V. W. S. Wong, A. M. Woltman et al., "Polymorphisms near IL28B and serologic response to peginterferon in $\mathrm{HBeAg}$-positive patients with chronic hepatitis B," Gastroenterology, vol. 142, no. 3, pp. 513-520, 2012.

[4] M. Roncato, P. A. Z. Ballardin, and V. R. Lunge, "Influence on its genotypes of the treatment for type B hepatitis," Revistas HCPA, vol. 28, pp. 188-193, 2008.

[5] E. Strauss, J. R. H. Sette, M. R. C. Nobre et al., Chronic Hepatitis B: Treatment. Design Guidelines, Associação Médica Brasileira e Conselho Federal de Medicina, Sao Paulo, Brazil, 2009.

[6] Ministério da Saúde, Secretaria de Vigilância em Saúde, Departamento de DST, AIDS e Hepatites Virais, Boletim Epidemiológico-Hepatites Virais. Ano III-no. 1. Ministério da Saúde, Brasília, DF, Brasil, pp. 8-10, 2012.

[7] S. R. S. S. Conde, L. J. P. Móia, M. S. B. Barbosa et al., "Prevalence of hepatitis B virus genotypes and the occurrence of precore mutation A-1896 and their correlation with the clinical presentation of chronic hepatitis in a population group of the Eastern Amazon region," Revista da Sociedade Brasileira de Medicina Tropical, vol. 37, pp. 35-36, 2004.

[8] G. C. Lv, W. J. Ma, L. J. Ying, X. Jin, L. Zheng, and Y. D. Yang, "Efficacy of telbivudine in HBeAg-positive chronic hepatitis B patients with high baseline ALT levels," World Journal of Gastroenterology, vol. 16, no. 32, pp. 4095-4999, 2010.

[9] M. S. Ferreira and A. S. Borges, "Advances in the treatment of hepatitis B," Revista da Sociedade Brasileira de Medicina Tropical, vol. 40, pp. 451-462, 2007.

[10] A. Balagopal, D. J. Thomas, and C. L. Thio, "Reviews in basic and clinical gastroenterology and hepatology," Gastroenterology, vol. 139, no. 6, pp. 1865-1876, 2010.

[11] M. C. Li, H. Y. Wang, H. Y. Wang, T. Li, and S. H. He, "Liposomemediated IL-28 and IL-29 expression in A549 cells and antiviral effect of IL-28 and IL-29 on WISH cells," Acta Pharmacologica Sinica, vol. 27, no. 4, pp. 453-459, 2006.

[12] K. Witte, E. Witte, R. Sabat, and K. Wolk, "IL-28A, IL-28B, and IL-29: Promising cytokines with type I interferon-like properties," Cytokine and Growth Factor Reviews, vol. 21, no. 4, pp. 237-251, 2010.

[13] G. Uzé and D. Monneron, "IL-28 and IL-29: newcomers to the interferon family," Biochimie, vol. 89, no. 6-7, pp. 729-734, 2007. 
[14] S. Commins, J. W. Steinke, and L. Borish, "The extended IL-10 superfamily: IL-10, IL-19, IL-20, IL-22, IL-24, IL-26, IL-28, and IL-29," Journal of Allergy and Clinical Immunology, vol. 121, no. 5, pp. 1108-1111, 2008.

[15] D. L. Thomas, C. L. Thio, M. P. Martin et al., "Genetic variation in IL28B and spontaneous clearance of hepatitis C virus," Nature, vol. 461, no. 7265, pp. 798-801, 2009.

[16] W. Li, Y. Jiang, Q. Jin et al., "Expression and gene polymorphisms of interleukin 28B and hepatitis B virus infection in a Chinese Han population," Liver International, vol. 31, no. 8, pp. 1118-1126, 2011.

[17] P. Bedossa and T. Poynard, "An algorithm for the grading of activity in chronic hepatitis C," Hepatology, vol. 24, no. 2, pp. 289-293, 1996.

[18] Centers for Diseases Control and Prevention, Epi Info, version 3. 5. 3, 2012, http://wwwn.cdc.gov/epiinfo/html/vendors.htm.

[19] M. Ayres, M. Ayres Jr., D. L. Ayres, and A. S. Santos, BioEstat 5.0: Statistical Applications in the Areas of Biological and Medical Sciences, Sociedade Civil Mamirauá, Belém, Brazil, 2007.

[20] L. Martin-Carbonero, N. I. Rallon, J. M. Benito, E. Poveda, J. Gonzalez-Lahoz, and V. Soriano, "Does interleukin-28B single nucleotide polymorphisms influence the natural history of hepatitis B?" AIDS Research and Human Retroviruses, vol. 28, pp. 1262-1264, 2012.

[21] L. J. Peng, J. S. Guo, Z. Zhang, H. Shi, and J. Wang, "IL28B rs12979860 polymorphism does not influence outcomes of hepatitis B virus infection," Tissue Antigens, vol. 79, no. 4, pp. 302-305, 2012.

[22] M. P. Martin, Y. Qi, J. J. Goedert et al., "IL28B polymorphism does not determine outcomes of hepatitis B virus or HIV infection," Journal of Infectious Diseases, vol. 202, no. 11, pp. 1749-1753, 2010.

[23] S. Ren, J. Lu, X. Du et al., "Genetic variation in IL28B is associated with the development of hepatitis B-related hepatocellular carcinoma," Cancer Immunology, Immunotherapy, vol. 61, pp. 1433-1439, 2012. 


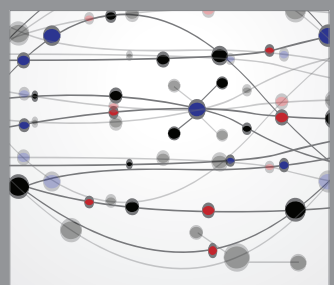

The Scientific World Journal
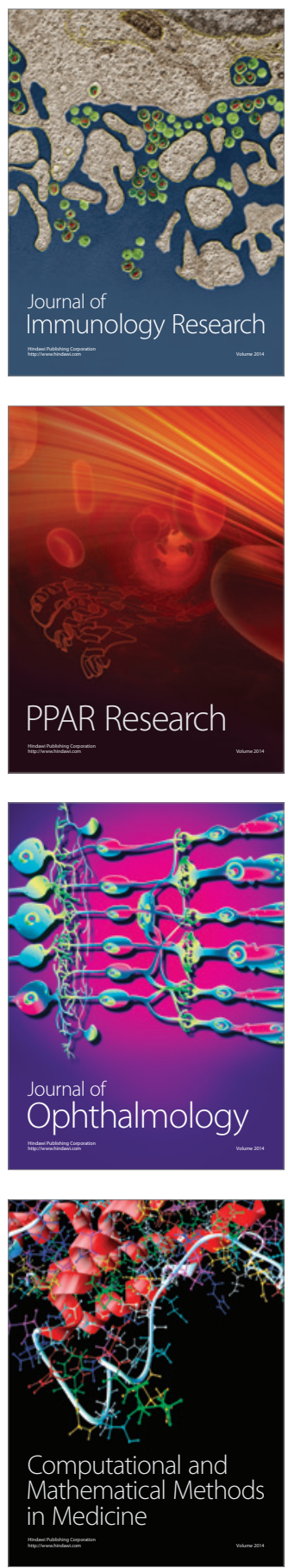

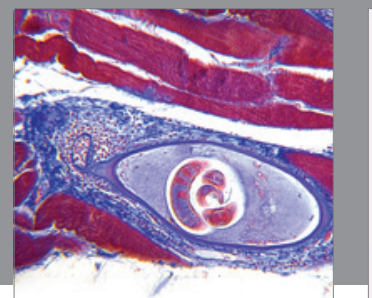

Gastroenterology

Research and Practice
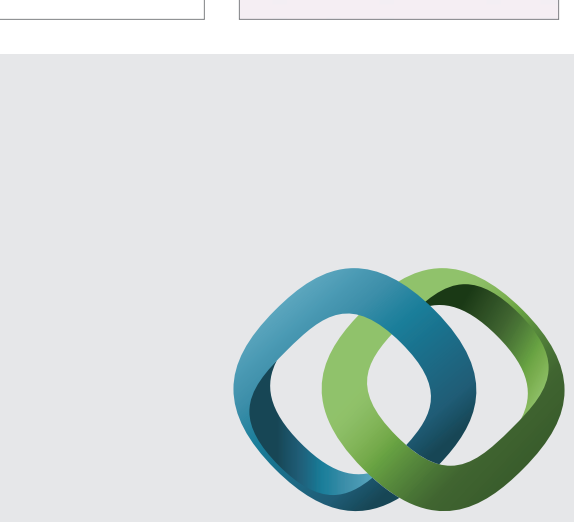

\section{Hindawi}

Submit your manuscripts at

http://www.hindawi.com
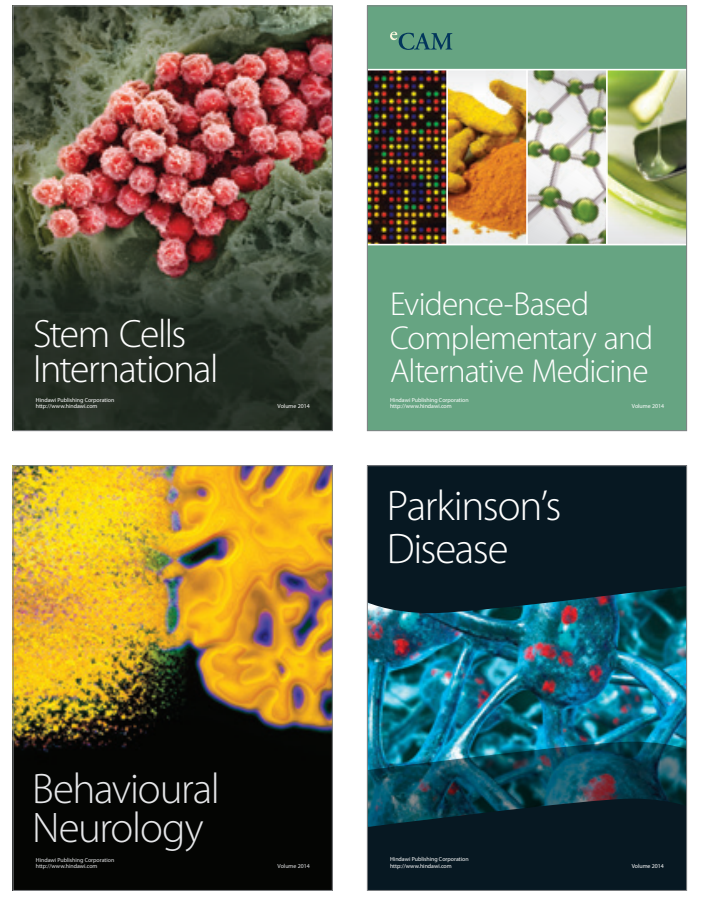
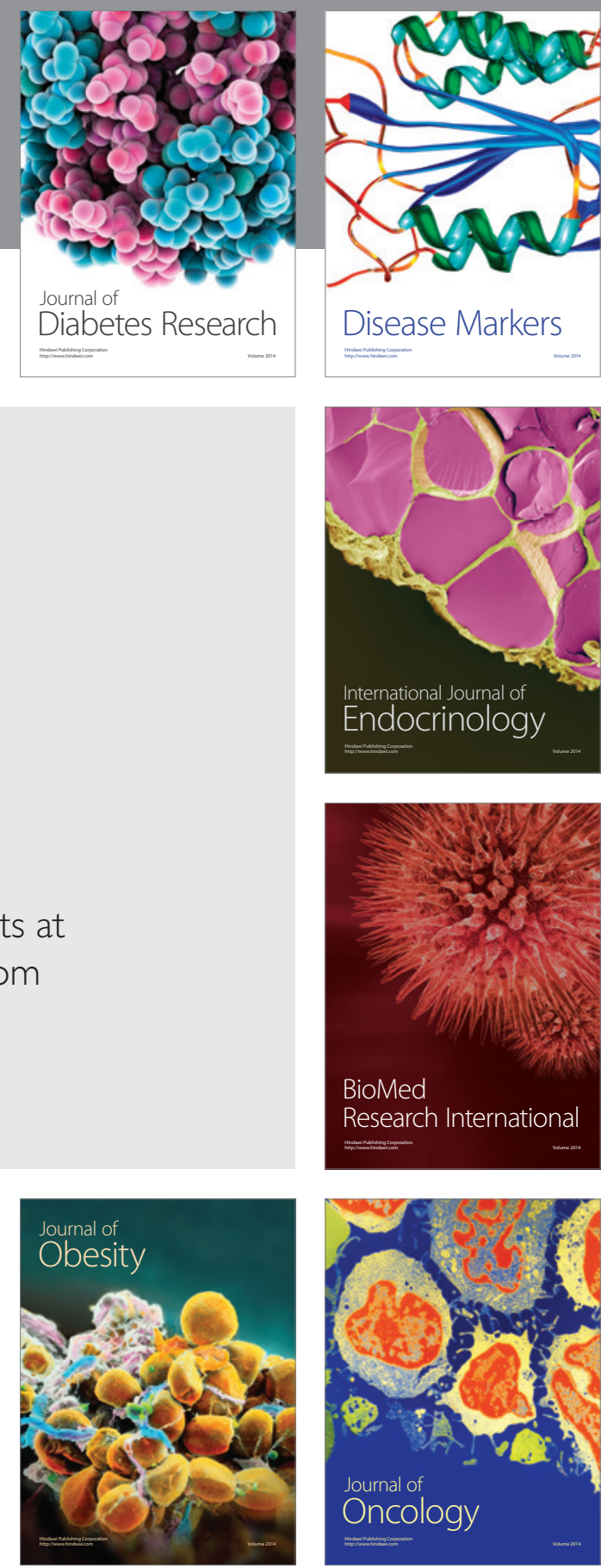

Disease Markers
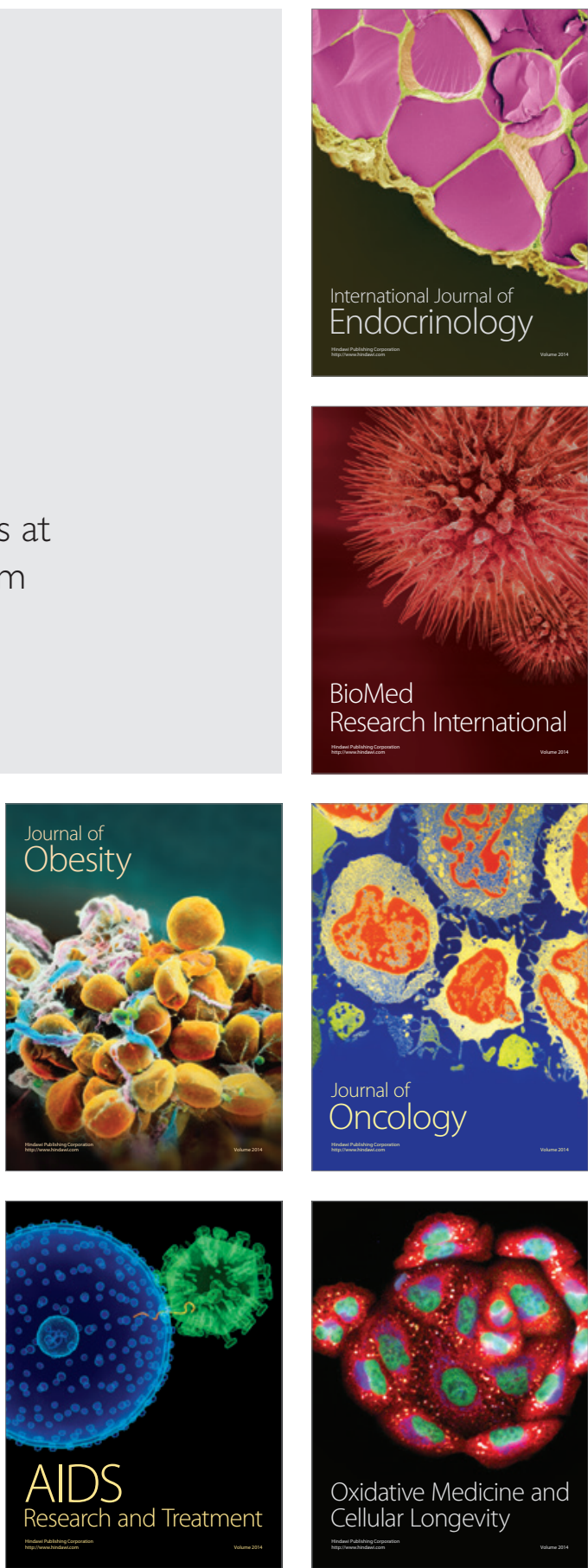